\title{
O uso das TIC no trabalho de professores universitários de língua inglesa
}

\section{The ICT use in the work of English language professors}

Glenda Cristina Valim de Melo

Universidade de Franca

Franca - São Paulo / Brasil

RESUMO: Este artigo apresenta as representações sobre o tipo de trabalho que docentes universitários de Língua Inglesa consideram realizar com as Tecnologias de Informação e Comunicação (TIC) em sala de aula. Os aportes teóricometodológicos estão embasados no Interacionismo Sociodiscursivo de Bronckart (2007; 2008), nas concepções de trabalho desenvolvidas pela Clínica da Atividade e Ergonomia e nas características de trabalho de Machado (2010). Participaram do estudo seis docentes universitários de Língua Inglesa que utilizam as TIC no trabalho. Os dados foram gerados via internet, via e-mails e Moodle. Cada participante produziu um texto em que relatou os usos que faria dessas ferramentas. Os resultados indicam que os docentes fazem usos semelhantes das ferramentas e que há impedimentos no uso das TIC para os docentes da universidade pública. PALAVRAS-CHAVE: Trabalho docente, Tecnologias de informação e comunicação, Professor universitário, Língua inglesa.

ABSTRACT: This article presents representations about the kind of work that university professors hope to achieve when using Information \& Communications Technology (ICT) in the classroom. The theoretical background is based on Socio-discursive Interactionism, theories about work as developed in Clinical Activity and Ergonomics and in the characteristics of work proposed by Machado (2010). Six English language professors that use ICT at work participated in the research project. Data were collected via internet, through e-mail or Moodle. Each participant provided a text on their experiences and the use of ICT. The results indicate that university professors use the ICT in the same way, butsome restrictions to this matter are appointed by public university professors.

KEYWORDS: Teacher's work, Information and communications technology, University professor, English language.

* glendamelo09@gmail.com 


\section{Trabalho Docente}

O objetivo deste artigo é apresentar as representações ${ }^{1}$ do tipo de trabalho que os docentes universitários de Língua Inglesa (doravante LI) consideram realizar com as Tecnologias de Informação e Comunicação (TIC) em sala de aula e o contexto de produção dos textos desses professores. Esses docentes foram divididos em dois grupos: aqueles que trabalham em universidades públicas e os que trabalham em universidades particulares para observamos os tipos de trabalho em contextos distintos.

Especificamente a respeito do ensino, de acordo com Bronckart (2009, p. 162), ele não é um sacerdócio e nem o professor deve ser visto como alguém iluminado. O ensino é um trabalho e o professor - como qualquer outro trabalhador - deve aprender a desenvolvê-lo e a capacitar-se para exercer tal cargo. O trabalho docente, de acordo com Amigues (2004, p. 45) é

um ofício e um trabalho como outro qualquer, apresenta-se, ao mesmo tempo, como uma atividade regulada, explícita ou implicitamente, como uma atividade contínua de invenção de soluções, e, enfim, como uma atividade coletiva.

Para compreender melhor o trabalho em sua totalidade, seria necessário considerar o ponto de vista "subjetivo do ator e o que ele constrói de modo mais ou menos conflitual para regular essa distância". Ainda para Amigues (2004, p. 40), a atividade docente não seria direcionada apenas ao aluno mas também à instituição a que o docente pertence, aos profissionais (secretário, diretor, coordenador etc.) com quem ele trabalha, aos responsáveis pelo aluno (pais, irmãos, avós, tios, tutores, entre outros). Ainda segundo o autor,

[...] a atividade do professor também busca seus meios de agir nas técnicas profissionais que se constituíram no decorrer da história da escola e do ofício do professor. Em outros termos, a atividade não é a de um indivíduo destituído de ferramenta, socialmente isolado e dissociado da história; pelo contrário, ela é socialmente situada e constantemente mediada por objetos que constituem um sistema (AMIGUES, 2004, p. 42).

\footnotetext{
${ }^{1}$ Vale ressaltar que para este artigo foi realizado um recorte de tese defendida no segundo semestre de 2010, na Pontifícia Universidade Católica - SP, sob orientação das professoras Dra. Anise D’Orange Ferreira e Dra. Anna Rachel Machado.
} 
Ao contrário, a atividade docente está inserida em um contexto sóciohistórico e é mediada por ferramentas, que podem ser equipamentos tecnológicos, lousa e material didático, bem como exercícios utilizados a serviço do ensino.

A respeito desse trabalho, Amigues (2004) ainda apresenta uma distinção entre tarefa e atividade:

- a tarefa, segundo o autor, é entendida como aquilo que deve ser feito "ela pode ser objetivamente descrita em termos de condições e de objetivo";

- a atividade é o que o sujeito "faz mentalmente para realizar uma tarefa, não sendo, portanto, diretamente observável, mas inferida a partir da ação concretamente realizada pelo sujeito".

No âmbito do trabalho, de acordo com o autor, a tarefa é determinada ou prescrita pelo outro - por exemplo, o Ministério da Educação -, e não pelo docente; por isso, há sempre uma distância entre o trabalho prescrito e o trabalho realizado pelo professor.

Na mesma perspectiva, Machado (2009, p. 37) apresenta uma série de características gerais do trabalho docente. Segundo a autora, esse trabalho:

- (a) é uma atividade situada, altamente influenciada pelas condições sócio-históricas de uma determinada sociedade;

- (b) é orientada por prescriçôes de vários níveis institucionais, do sistema educacional mais amplo aos sistemas de ensino (PCN, por exemplo, no caso do ensino de gêneros textuais) e por modelos do agir, historicamente construídos por seu coletivo de trabalho;

- (c) é tratada pelas prescriçôes de forma impessoalizada, já que as prescrições são dirigidas a todos os trabalhadores, para qualquer situação de trabalho, e não ao indivíduo;

- (d) é pessoal, própria de cada professor, que, para realizá-la, mobiliza seu ser integral em suas múltiplas dimensões (físicas, cognitivas, linguageiras, afetivas etc.);

- (e) é uma atividade finalizada, pois tem por objetivo a construção de um ambiente propício à aprendizagem de determinados conteúdos pelos alunos e ao desenvolvimento de determinadas capacidadesa eles relacionadas; 
- (f) é uma atividade instrumentada, pois o professor se utiliza de instrumentos materiais ou simbólicos, derivados de artefatos, a fim de atingir seus objetivos;

- (g) é uma atividade interpessoal que se desenvolve entre vários sujeitos, quer estejam presentes (alunos, por exemplo), quer estejam ausentes (direção, coordenação, colegas etc.) (grifos da autora).

A FIG. 1, elaborada por Machado (2010), sintetiza o que foi explicado acima:

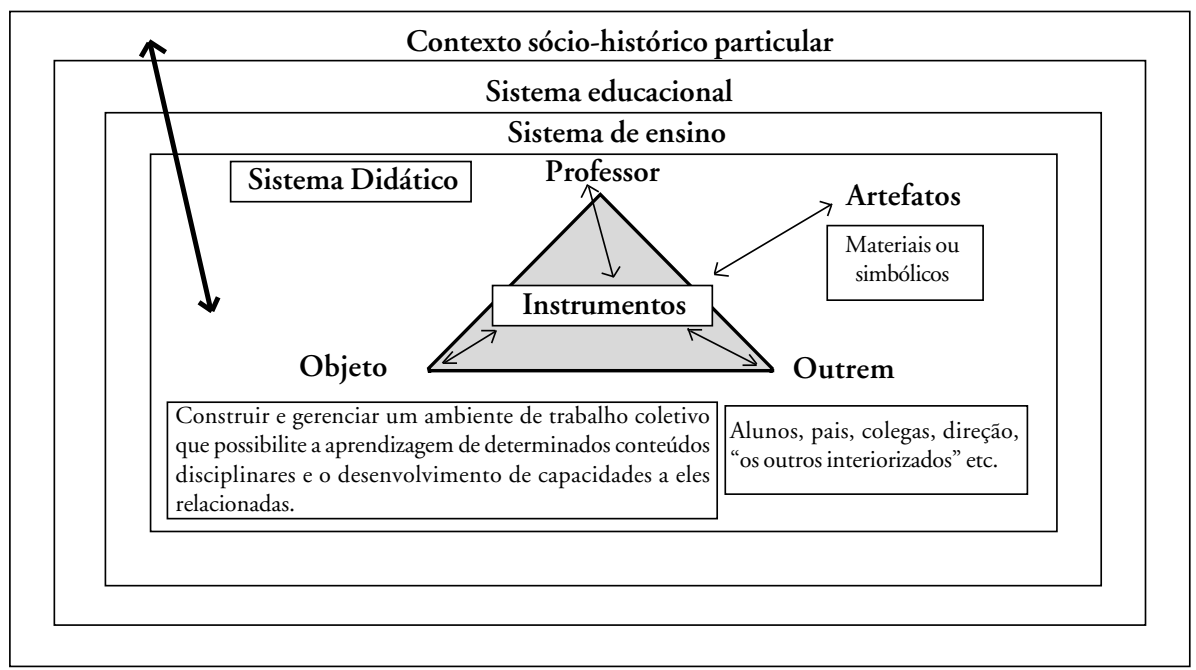

FIGURA 1 - Esquema dos elementos constituintes do trabalho do professor em situação de sala de aula.

Concordando com a concepção de trabalho docente proposta por Amigues (2004) e suas características gerais, indicadas por Machado (2009; 2010), compreendemos que as concepçóes de trabalho docente e suas características estão diretamente relacionadas a uma das características do trabalho: a presença de instrumentos; voltemo-nos para o uso das TIC no trabalho do professor universitário do curso de Letras.

\section{Uso das TIC no trabalho docente universitário}

Quanto ao ensino superior, especificamente no curso de Letras, os pareceres CNE / CES 492/2001, do Ministério da Educação, propõem a inserção das TIC nos projetos pedagógicos: “[...] o curso de Letras deve 
contribuir para o desenvolvimento das seguintes competências e habilidades [...] utilização dos recursos da informática [...]" (MEC, 2001, p. 30).

Em vista disso, o Ministério da Educação atribui às universidades públicas e / ou particulares o papel de propiciar acesso aos conhecimentos tecnológicos aos seus graduandos em Língua Estrangeira ou Língua Materna. Nas diretrizes curriculares do Ministério da Educação em relação ao curso de Letras, a universidade é vista também "como instância voltada para atender às necessidades educativas e tecnológicas da sociedade [...]" (CNE / CES492/2001, 2001, p.23). Devido a isso, novas habilidades poderão ser construídas, para lidar com as diferentes realidades profissionais, incluindo a utilização das TIC. Os pareceres do MEC tornaram o conhecimento computacional uma exigência para os currículos de Letras. Segundo Abreu-Tardelli (2004), em virtude dessas novas habilidades, o docente universitário pode sentir a necessidade de aprender e / ou atualizar os conhecimentos na área computacional.

Em relação aos pareceres e diretrizes do MEC, Abreu-Tardelli (2004), ao analisar o Decreto 2.494/1998, reafirma que há uma representação de que a tecnologia em si resolveria o problema da educação e propiciaria a diminuição de fronteiras entre a docência e a tecnologia. Segundo ela, o professor aparece apenas como aquele que executa tarefas, não havendo diferença se ele é um tutor ou um educador. A tecnologia, desse modo, é representada como suprema e como o fator que conduz o ensino. Para a autora, essas representações revelam um olhar da legislação brasileira em relação ao uso da tecnologia que desconsidera o fato de que seria necessário que as TIC deixassem de ser artefatos e passassem a ser instrumentos aplicáveis ao ensino.

Pensando as TIC como instrumento, primeiramente abordamos a nomenclatura artefato e instrumento. Verillon e Rabardel (1995, p. 80) dizem que

[...] o instrumento não existe por si próprio, ele se torna um instrumento quando o sujeito tem a capacidade de apropriá-lo e integrá-lo a sua atividade. Mais precisamente, um instrumento pode ser considerado uma extensão do corpo, um órgão funcional feito por um componente de artefato (um artefato ou a fração de uma ferramenta mobilizada pela atividade) e por um componente psicológico. O órgão construído, nomeado gênese de instrumento, é um processo complexo que requer tempo e ligação entre as características do artefato (suas 
potencialidades e suas restrições) e atividade do sujeito, seu conhecimento e seu antigo método de trabalho. ${ }^{2}$

Complementando a questão, Machado (2010), em curso promovido pela Coordenadora de Estudos e Normas Pedagógicas (CENP), afirma que os conceitos de artefato e instrumento são aceitos por pesquisadores neovygotskyanos. A pesquisadora esclarece que o primeiro - o artefato - se refere aos objetos materiais e simbólicos socialmente construídos que são colocados à disposição do ser humano para mediar suas ações sobre o outro ou o meio, visando conseguir ou atingir algumas finalidades. $\mathrm{O}$ segundo - o instrumento - é uma entidade mista que se constitui de parte do artefato, mas que passa a ser apropriado pelo sujeito, que o transforma, de acordo com sua finalidade; ele deixa, então, de ser artefato para se tornar instrumento.

Se relacionarmos os conceitos de artefato, de instrumento e do trabalho docente, discutidos previamente, as TIC seriam os artefatos que o docente de LI poderia utilizar em sala de aula. Enquanto artefato, o seu uso poderia ser precário e gerar conflitos com professor, visto que não teria sido por ele apropriado. Para ser capaz de orientar, definir e criar diferentes possibilidades de uso, o docente precisa, primeiramente, apropriar-se dos recursos tecnológicos, para então orientar os graduandos de Letras quanto ao ensino de LI mediado pelas ferramentas computacionais. Como instrumento, as TIC seriam utilizadas conforme a utilidade, finalidade e necessidade do trabalhador professor.

Um fator que poderia contribuir para que essa apropriação aconteça é a inclusão do professor no processo de informatização da educação, como propõe Martinez (2004, p. 100). Segundo ele, "os educadores podem e devem participar das decisões sobre o processo de equipar. É indispensável envolvêlos no planejamento e desenvolvimento dos programas de integração das TIC." Ao ser envolvido no processo, o docente tomaria ciência de que as TIC foram incluídas na educação com base em experiências de outrem, analisaria sua

\footnotetext{
2 "[...] the instrument does not exist in itself, it becomes an instrument when the subject has been able to appropriate it for himself and has integrated it with his activity". More precisely, an instrument can be considered as an extension of the body, a functional organ made up of a tool component (a tool, or a fraction of a tool mobilized in the activity) and a psychological component. This organ construction, named instrumental genesis, is a complex process, needing time, and linked to the tool characteristic (its potentialities and its constraints) and to the subject's activity, his/her knowledge, and former method of working".
} 
possível contribuição para a execução de suas tarefas, verificaria a viabilidade de uso no seu contexto específico de trabalho e definiria objetivos de uso dos recursos tecnológicos com base na sua experiência em sala de aula.

Especificamente para que o docente universitário de LI, objeto desta pesquisa, faça uso desses instrumentos em sua prática pedagógica, ele precisaria estar relacionado ao ensino de LI e também à formação de professores. Sem a devida apropriação das TIC, o docente poderia ter conflitos ao desempenhar suas tarefas e elas não contribuiriam, assim, para uma melhoria na qualidade de seu trabalho. Entendemos que essa apropriação não deve ocorrer em um prazo curto; pode levar algum tempo e ocorrer apenas quando e se o trabalhador professor perceber uma finalidade clara do uso dos recursos computacionais para seu proveito. Assim, ao perceber os benefícios, ele poderia escolher que ferramenta computacional utilizar e adequá-la ao contexto em que trabalha e as tarefas que executa. Além disso, ele poderia optar por usá-la ou não, embasado nos conhecimentos, artigos e pesquisas que tenha lido ou desenvolvido, e não em achismos ou modismos de época. No entanto, sem a apropriação do instrumento TIC, nenhuma dessas possibilidades poderiam ser colocadas em prática.

Em suma, para esta investigação observamos que as concepções de trabalho, de trabalho docente, as características propostas por Machado (2009; 2010) e o uso de instrumentos como as TIC no ensino são relevantes para compreendermos o ensino como trabalho. Além disso, as tarefas e atividades desse trabalho poderiam influenciar na formação do graduando de LI e contribuir para as tarefas que o docente universitário teria de realizar.

\section{O Professor Universitário e as Condições de Trabalho}

Uma das preocupações em relação ao professor universitário, segundo Pimenta e Anastasiou (2008), é a sua formação para o ensinar. Da mesma forma, como aponta Rozendo (1999, p. 15), há uma lacuna na formação desse docente, que se caracteriza por ser "um especialista no seu campo de saber", mas não necessariamente um profissional com formação didático-pedagógica. Seguindo esse ponto de vista, Vidal (2002, p. 55) diz que há muitos professores universitários que têm uma preparação pedagógica deficiente ou nula: 
[...] é sabido que muitos professores universitários tiveram pouca ou nenhuma preparação didático-pedagógica. Nem parece ser um item tão importante assim, pois, ao se contratarem professores para o ensino superior, exigem-se títulos, certificados de experiência, mas nenhuma comprovação de bom desempenho didático em sala de aula.

Fernandes (2001), por sua vez, afirma que o professor do Ensino Fundamental e Médio precisa ter conhecimentos na área pedagógica; no entanto, esse saber é considerado desnecessário para o docente universitário, pois a este bastaria o conhecimento técnico e / ou o desenvolvimento de pesquisas. Reforçando esse ponto, Pimenta e Anastasiou (2008) remetem à legislação vigente, enfatizando que nela não se aponta a necessidade do conhecimento didático-pedagógico. Segundo as autoras, a LDBEN nº $9.394 / 96$ e o decreto 2.207/97, que definem as diretrizes e bases para o ensino superior federal, sugerem que, para lecionar, faz-se necessária apenas uma pós-graduação, de preferência em programas de mestrado e de doutorado.

No entanto, como há uma pequena parcela de docentes com tais titulações, algumas instituições oferecem disciplinas como Metodologia de Ensino Superior que poderiam sanar "a falta de formação pedagógica”. Os conhecimentos didáticos não são considerados relevantes para uma boa parte do corpo docente, independentemente da instituição em que trabalhem. Discordando dessa visão, corroborando Fernandes (2001), Vidal (2002) e Carneiro (2006), Pimenta e Anastasiou enfatizam que é senso comum a concepção de que o docente do ensino superior deva dominar o conteúdo técnico para reunir em si condições de exercer a docência. O ensinar é visto, então, como "dizer um conteúdo a um grupo de alunos reunidos em sala de aula” (PIMENTA; ANASTASOU, 2008, p. 142).

Sobre a formação docente, Pimenta e Anastasiou (2008) apresentaram dados estatísticos que incluem informações sobre o trabalho docente, embasados no Censo da Educação Superior de 1998, realizado pelo Instituto Nacional de Estudos e Pesquisas Educacionais Anísio Teixeira (INEP). Como o Instituto apresentou dados mais recentes, seguindo o mesmo entendimento das autoras e com base no Censo da Educação Superior de 2007, geramos os gráficos mostrados a seguir. $O$ primeiro deles (GRAF. 1) apresenta um quadro da formação de docentes universitários no Brasil: 


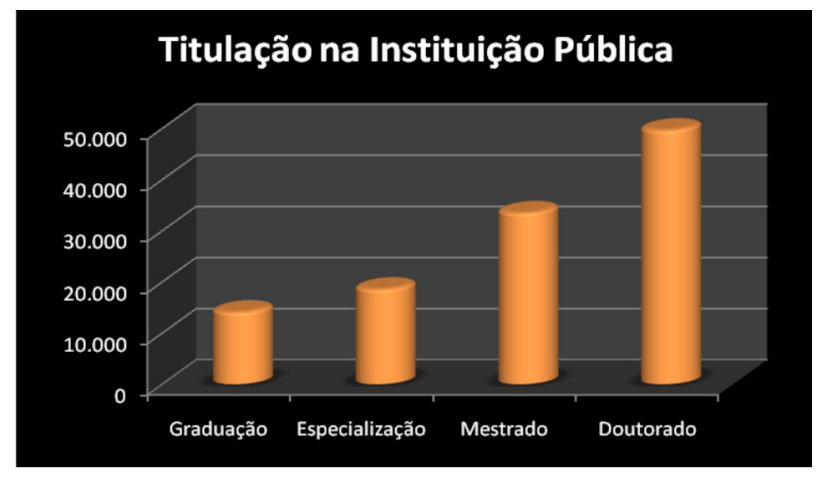

GRÁFICO 1 - Titulação docente nas instituições públicas no Brasil

Nas instituições públicas, observa-se um número maior de doutores. Ao compararmos o GRAF. 1 ao GRAF. 2, podemos constatar que há um número maior de mestres e especialistas nas instituiçôes particulares:

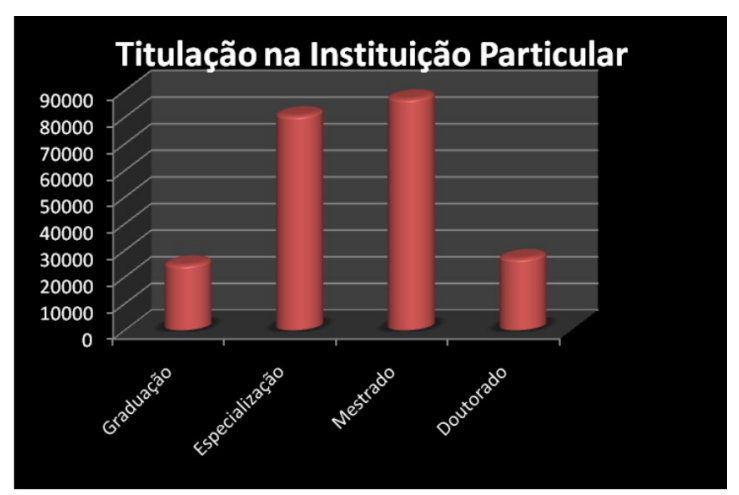

GRÁFICO 2 - Titulação docente nas instituições particulares no Brasil

A legislação exige 1/3 (um terço) de mestres e doutores. Se pensarmos nos custos de uma universidade particular para adequar-se a tal percentual, manter esse número de doutores pode ser mais caro; esta pode ser uma explicação para o número reduzido desses profissionais. Isso não ocorre em instituições públicas, onde a contratação depende de aprovação em concurso, com base em edital, em que a exigência de titulação pode ser o doutoramento.

A respeito dos possíveis locais de trabalho do professor universitário, Pimenta e Anastasiou (2008) apontam, embasadas na Lei de Diretrizes e Bases (LDB) 9.394/96, as universidades, os centros universitários, as faculdades integradas, os institutos e escolas superiores, cada um com características, foco 
e objetivos de ensino diferentes. O GRAF. 3 apresenta a relação entre o número de instituições particulares e públicas de ensino superior (municipais, estaduais e federais), em todo o Brasil:

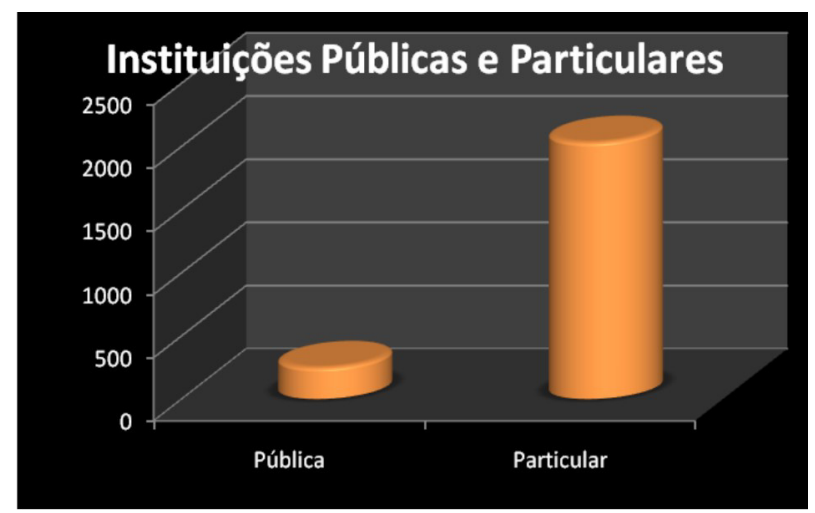

GRÁFICO 3 - Instituições públicas e particulares de ensino superior no Brasil

No GRAF. 3, observamos a diferença entre instituições públicas e particulares. Uma explicação pode ser atribuída a um aumento na procura de vagas em cursos superiores por alunos das classes menos favorecidas e / ou oriundos de escolas públicas. Como o processo seletivo nas instituiçôes públicas é mais complexo e o número de vagas não supre a demanda, as particulares encontraram um contexto apropriado de expansão de seus negócios.

Acrescenta-se a isso o fato de algumas dessas instituições oferecerem mais de um processo seletivo para o ingressante, como vestibular, análise de histórico e redação, classificação em processos de avaliação oficiais - como o ENEM. As consequências desse crescimento podem ser detectadas no mercado de trabalho, um número maior de pessoas com diploma de ensino superior - o que não corresponde, necessariamente, a uma formação de qualidade.

Essa discrepância está presente no resumo técnico do INEP de 2007. Com base nesse relatório, é possível perceber um crescimento no número de instituiçôes particulares de ensino superior nos últimos anos: em 2002, 1.442; em 2003, 1.652; em 2004, 1.789; em 2005, 1.934; em 2006, 2.022; e em 2007, 2.032.

No entanto, o crescimento de instituições particulares não significa, necessariamente, um aumento na qualidade do ensino superior, tampouco do trabalho docente.

O trabalho e às tarefas do docente são definidos com base no tipo de instituição em que ele está inserido. Por exemplo, em uma universidade, o docente tem de dividir seu trabalho entre ensino, pesquisa e extensão; já em 
uma escola superior, o foco é o ensino; a pesquisa torna-se opcional. Assim, as tarefas a cumprir não são as mesmas, pois elas estão diretamente relacionadas ao contexto de trabalho. De acordo com Morosini (2000, p. 14),

No caso da Educação Superior, um dos condicionantes mais fortes da docência universitária é o estabelecimento em que o professor exerce sua atividade. Dependendo da missão da instituição e das consequentes funçôes priorizadas, o tipo de atividade do professor será diferente. Dependendo da mantenedora, governamental ou privada, com administração federal, estadual ou municipal, o pensar e o exercer a docência serão diferentes, com condicionantes diferenciados também.

Nessas diferentes instituições, as formas de ingresso, de contrato de trabalho, de vínculo e de jornada de trabalho também são distintos.

Quanto ao vínculo e à jornada de trabalho, nas instituiçôes públicas o docente passa por um período probatório e, ao final, é confirmada ou não a sua efetivação mediante uma avaliação realizada por um de seus pares. $\mathrm{O}$ professor efetivo pode ser contratado para atuar em regime integral / exclusivo ou parcial. Em tempo integral, o docente deve trabalhar nos três pilares já citados anteriormente - ensino, pesquisa e extensão. Nas instituições particulares, mesmo em se tratando de universidade, o contrato pode ser estipulado pela quantidade de aulas ministradas ou pelo tempo de permanência em sala de aula, como relatam Pimenta e Anastasiou (2008), havendo algumas instituições particulares que seguem um regime parecido ao das públicas.

Em relação ao regime de trabalho, o GRAF. 4 mostra as diferenças entre as instituiçôes públicas e as particulares no Brasil. Nas públicas, o regime de tempo integral (TI) se destaca; nas particulares, há um maior número de professores horistas:

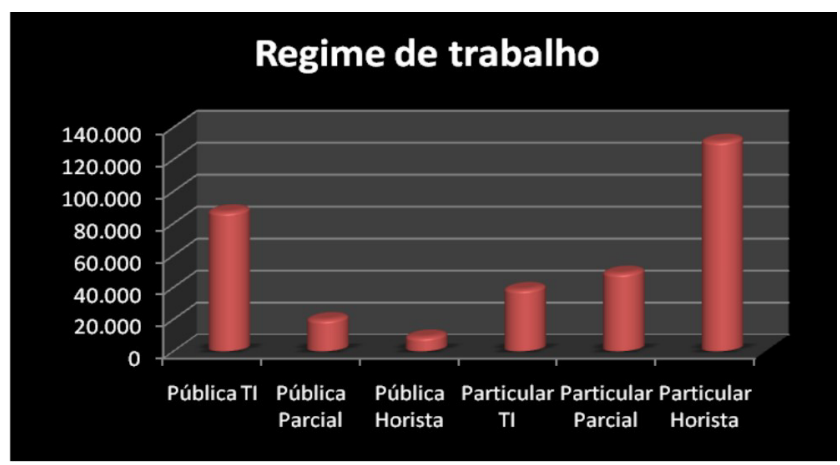

GRÁFICO 4 - Regime de trabalho no Brasil 
Segundo Pimenta e Anastasiou (2008), com as atuais exigências da legislação as universidades particulares devem ter professores que cumpram o regime integral ou parcial; contudo, o que se nota é que a maioria dos docentes trabalha como horista. Cabe salientar que, no que tange à universidade particular, regime integral não é sinônimo de dedicação exclusiva, como ocorre na universidade pública. Retomando o docente horista, ele, frequentemente, trabalha em vários institutos de ensino superior e, em consequência disso, está ausente das decisões e reuniões nas quais poderia trocar experiências, discutir currículos e projetos pedagógicos.

Em vista do exposto observamos que, independentemente do regime de trabalho e da instituição, as prescrições - por exemplo, o parecer CNE / CES 492/2001 do Ministério da Educação - sugerem que as TIC sejam incorporadas aos projetos pedagógicos e aos currículos dos cursos de Letras, desconsiderando a apropriação desses recursos pelos docentes. Por fim, podemos perceber que o trabalho do professor universitário depende da instituição em que ele trabalha, de sua formação, do regimento, do contrato de trabalho e das prescrições diversas. Esses aspectos influenciariam nas tarefas do professor, na qualidade de seus serviços e na sua formação.

\section{Interacionismo Sociodiscursivo}

O último pressuposto teórico que embasa esta pesquisa éo Interacionismo Sociodiscursivo, ISD, que defende que o humano deve ser estudado pela integração de várias disciplinas, considerando o contexto social em que está inserido, seu comportamento nesse contexto, a linguagem desse humano e a situação de uso dessa linguagem no contexto $x$ ou $y$. Segundo Bronckart (2007, p.20), essa ciência é "centrada na dinâmica formadora das práticas de linguagem", porque é pela linguagem que representamos o universo dinâmico em que estamos inseridos.

Assim, no ISD são desenvolvidos trabalhos teóricos e empíricos que destacariam o papel fundador das atividades linguageiras no desenvolvimento humano. Bronckart (2006, p. 129) observa que, para explicar o funcionamento psicológico e o desenvolvimento humano, é necessário fazer uma análise de três níveis:

- o dos pré-construídos: como os fatos sociais, as atividades coletivas gerais e as atividades de linguagem; 
- o dos processos de mediação formativa, sobretudo, esses relacionados à educação nas instituições escolares;

- o do desenvolvimento, relativo ao desenvolvimento das pessoas e de suas capacidades.

Concordando com o quadro epistemológico do ISD, compreendemos que, para se investigar o trabalho docente realizado com as TIC por professores universitários que ministram aulas de LI e fazem uso dessas ferramentas no trabalho, é pertinente considerar a integração entre as áreas do saber, já que essa integração nos permitiria perceber um ser mais completo, inserido em um contexto social, dotado de capacidades e conhecimentos e que constrói suas representaçôes do mundo na e pela linguagem. Para este estudo especificamente, o ISD nos permite congregar aportes teóricos das Ciências do Trabalho e de estudos sobre o ensino de LI mediado pelas TIC.

Além disso, interessa-nos, nessa vertente do interacionismo, a concepção da linguagem que exerce um papel essencial, ou seja, que é na e pela linguagem que são construídas as representações do mundo, incluindo aqui as representações sobre o tipo de trabalho realizado com as TIC. Para detectá-las, assumimos os procedimentos de análise do ISD, ${ }^{3}$ que englobam, primeiro, o contexto de produção; segundo, o nível organizacional; terceiro, o nível enunciativo, e por último, o nível semântico.

\section{Metodologia de Pesquisa}

A análise dos resultados está embasada nos aportes teórico-metodológicos do ISD (BRONCKART, 2006, 2008; MACHADO; BRONCKART, 2009), primeiramente porque essa abordagem considera a linguagem um elemento central, essencial e decisivo para o desenvolvimento humano; em segundo lugar, porque considera que seja possível identificar nos textos as representações construídas pelos participantes dessa investigação; e em terceiro, ao fato de que as ações humanas são consideradas em suas dimensões sociais e discursivas.

Os participantes da pesquisa foram divididos em dois grupos:

Grupo 1: 3 professores(as) universitários(as) de Língua Inglesa, que trabalhavam no mínimo há 5 anos em universidade pública estadual ou federal e utilizavam as TIC em sua prática pedagógica.

\footnotetext{
${ }^{3}$ Os pesquisadores do grupo ALTER PUC-SP têm discutido e abordado detalhadamente, em artigos e livros, esses procedimentos que não serão mencionados aqui.
} 
Grupo 2: 3 professores(as) com as mesmas qualificações anteriores quanto à formação, ao tempo de serviço e ao uso das TIC, mas que trabalhavam no mínimo há 5 anos em universidade particular.

\section{Grupo 1}

- Karina: formada em Letras - Português e Inglês (bacharelado e licenciatura), pela Universidade Federal do Rio de Janeiro (UFRJ), com especialização em Língua Inglesa, mestrado em Letras AngloGermânicas pela mesma instituição e doutorado em Linguística Aplicada (2004), pela Pontifícia Universidade Católica de São Paulo. Desde 1994, ela trabalha em uma universidade pública.

- Simone: em 1993, aos 19 anos, começou a trabalhar como professora de LI. Hoje é professora adjunta no Instituto Tecnológico da Aeronáutica, onde ministra disciplinas como Prática de Inglês Oral, Inglês Instrumental 1 e 2 e Tecnologia e Sociedade há mais de cinco anos. É colaboradora do programa de pós-graduação da Universidade de Taubaté, onde ministra módulos nos cursos de Especialização e no Mestrado. Desenvolve pesquisas na área de Educação e Tecnologia. De acordo com o seu currículo Lattes, ela graduou-se em 1983 em Letras, pela Universidade Estadual de Campinas; fez especialização em Arte e Tradução pela Pontifícia Universidade Católica de São Paulo; tem mestrado e doutorado em Linguística Aplicada e Estudos da Linguagem pela Pontifícia Universidade Católica de São Paulo.

- Samuel: também se formou em instituições públicas de ensino superior, tem licenciatura plena em inglês e suas respectivas literaturas pela Universidade Federal da Paraíba; tem Mestrado em Linguística Aplicada pela Universidade Estadual de Campinas e Doutorado em Estudos Linguísticos pela Universidade Federal de Minas Gerais. Coordenou o projeto Espaço Interação, que desenvolve atividades no laboratório de estudos polifônicos em um Instituto de Letras de uma universidade pública. Suas pesquisas estão centradas na área de Linguagem, Texto e Discurso.

\section{Grupo 2}

- Adriana: licenciada e bacharel em Língua e Literatura Inglesa; licenciada e bacharel em Língua e Literatura (Tradução). Fez mestrado e doutorado 
em Linguística Aplicada e Estudos da Linguagem na Pontifícia Universidade Católica de São Paulo. Terminou o pós-doutorado em Linguística Aplicada em 2008, na Universidade Estadual de Campinas, onde estudou o letramento digital. Ministra disciplinas como Língua Inglesa: Esferas do Cotidiano, Prática Oral 4, Leitura Intensiva 2, Tecnologias Digitais, entre outras. Trabalha em uma instituição particular de ensino superior há mais de cinco anos na graduação, pósgraduação (Lato e Stricto sensu) e na coordenação de curso (graduação). É pesquisadora da área de Ensino de Línguas mediado pelo computador.

- Fernanda: graduada em Letras, Tradutor e Intérprete; especialista em Gramática da Língua Inglesa e Mestre em Linguística. Ministra disciplinas como Prática da Tradução, Versão em Língua Inglesa, Inglês Instrumental, Informática Aplicada à Tradução. Trabalhou em várias instituições particulares de ensino superior, ministrando aulas de inglês instrumental em cursos de graduação em Ciência da Computação, Comércio Exterior, Moda e Farmácia. Em 2002, em uma universidade particular, foi responsável pela montagem de uma disciplina em que os alunos do curso de Tradutor tivessem contato com as principais ferramentas computacionais. Trabalha há mais de cinco anos em uma instituição particular na graduação, na coordenação da pós-graduação Lato sensu. Faz parte de um grupo de pesquisa na área de texto e discurso.

- Flor: graduada em Letras Português / Inglês e especialista em Língua Inglesa pela Universidade de Franca. Em 2003, finalizou o mestrado em Linguística e Língua Portuguesa na Universidade Estadual Paulista Júlio Mesquita Filho. Já lecionou língua inglesa em institutos de língua e, desde 1998, é docente do curso de Letras e da especialização em Língua Inglesa, de uma universidade particular. Também ministra aulas de literatura norte-americana e inglesa em um centro universitário, além de ser professora efetiva no ensino fundamental e médio em escola pública.

Os dados analisados foram gerados por meio da plataforma Moodle, especificamente, pelo recurso diário, por e-mail e por processador de texto. Cada participante escreveu um texto, sob o título Vivência Profissional, com base nas seguintes instruções: 
Olá Fulano(a),

Espero que esteja tudo bem com você.

Por favor, utilize esse espaço parame contar uma de suas aulas com o uso das Tecnologias de Informação e Comunicação.

Gostaria aindade conhecer mais sobresua formação acadêmica e experiências profissionais. Comente esses tópicos.

Os dados da pesquisa obtidospor meio de seus comentários serão tratados de modo a manter sua identidade anônima. Obrigada pela sua colaboração e gentileza!

Abraços,

$\operatorname{xxxxx}$

FIGURA 1 - Instruções

Após a geração de dados, primeiramente fizemos uma análise das instruções da pesquisadora. Depois disso, levantamos hipóteses sobre o contexto de produção, verificando em que contexto as produções de texto dos participantes foram elaboradas. A seguir, observamos a infraestrutura dos textos, levantando o seu plano global e os tipos de discurso. Na sequência, centramo-nos no nível enunciativo, especificamente no emprego de pronomes pessoais. Por último, verificamos o nível semântico. Nos textos, levantamos as representaçôes construídas sobre o tipo de trabalho que os participantes diziam fazer com as TIC. Neste artigo, apresentamos apenas os recortes do contexto de produção e do nível semântico.

Para tornar ágil o trabalho de levantamento linguístico de elementos tais como verbos, pronomes, artigos e sujeito, entre outros, foi utilizado o Tropes, ${ }^{4}$ versão 6.2 , que é um programa de análise textual que visa extrair as principais informaçōes de um texto, considerando os aspectos lexicais, semânticos e sintáticos.

\section{Resultados}

As produçōes textuais dos participantes foram elaboradas durante o ano de 2008. A participante Karina utilizou a plataforma Moodle para produzir os seus textos; Simone fez uso dessa plataforma e do e-mail; Samuel usou um processador de texto e $e$-mails para encaminhar suas narrativas. Já Adriana e

${ }^{4}$ Informações sobre o programa Tropes podem ser encontradas em: <http:// www.semantic-knowledge.com/tropes.htm>. 
Fernanda fizeram uso da plataforma Moodle, enquanto Flor recorreu ao processador de texto e ao e-mail. Os participantes que utilizaram os recursos computacionais no momento da produção poderiam, dependendo da sua preferência, estar conectados à internet ao produzirem seus textos.

Outro fator considerado relevante é o tempo de produção. No Moodle, o usuário ficaria conectado pelo tempo determinado pelo servidor da PUCSP, isto é, de 20 a 30 minutos. Transcorrido esse tempo, o programa era encerrado e então um novo $\log$ in era solicitado. Para realizar qualquer alteração em seu texto, o participante deveria conectar-se à plataforma para fazê-lo. Karina e Simone, por exemplo, tinham um tempo específico, determinado pelo próprio provedor do Moodle, para continuar online e elaborar os seus textos.

Ao usar um editor de texto o participante teria mais tempo para organizar sua produção textual, escrevê-la e enviá-la quando desejasse, havendo também a possibilidade de reler e retomar sua produção antes da versão final. Esse é o caso de Samuel, que utilizou o processador de texto e o e-mail, por um tempo necessário para a escritura dos seus textos.

De acordo com os dados registrados no programa Moodle, no grupo de docentes pertencentes às universidades públicas, a participante Simone produziu o texto Vivência Profissional no dia 30 de abril de 2008, quarta-feira, às $12 \mathrm{~h} 44$. Além do dia mencionado, Simone efetuou o seu $\log$ in nos dias 7 de abril e 5 de maio de 2008. A participante Karina escreveu o texto Vivência Profissional no dia 30 de abril de 2008 , quarta-feira, às 18 h53. Além do dia citado, Karina efetuou seu $\log$ in no programa Moodle nos dias 11, 18 e 27 de março, e no dia 2 de abril. Os horários indicam que ela registrou suas produçôes ao final da tarde. Já o participante Samuel produziu seus textos no processador de texto Word e os enviou via e-mail. Segundo registrado no ícone Propriedades, ele criou o seu texto no dia 10 de abril de 2008, quinta-feira, às 13 h02; o documento foi aberto novamente no dia 26 de abril, sábado, às 09h29, e enviado à pesquisadora às $9 \mathrm{~h} 30$ do mesmo dia.

Com base nos dados da dessa plataforma, no grupo dos docentes pertencentes às universidades particulares, a participante Adriana visitou apenas o seu espaço - o fórum, o perfil da pesquisadora, a página principal e as instruçôes; ela produziu o seu primeiro texto no dia 16 de março de 2008, domingo, às $22 \mathrm{~h} 38$. Tendo como suporte os horários registrados, Adriana escreveu seus textos à noite, em horários em que poderia estar em casa ou no trabalho. A participante Fernanda elaborou seu primeiro texto no dia 30 de 
junho de 2008, segunda-feira, às 22h44. Já a participante Flor produziu o seu texto no processador de texto Word. Segundo o ícone Propriedades do arquivo, ele foi criado no dia 30 de abril de 2008, quarta-feira, às $02 \mathrm{~h} 45$ da manhã; o documento foi aberto novamente no mesmo dia, às $11 \mathrm{~h} 08 \mathrm{~min}$ e enviado à pesquisadora às $11 \mathrm{~h} 17$.

Quanto ao nível semântico, embasados nas características de trabalho docente levantadas por Machado (2009; 2010), seguimos para as representações do tipo de trabalho que os docentes universitários de LI consideram realizar com as TIC em sala de aula. Em primeiro lugar, vale ressaltar que as tarefas dos participantes deste estudo estão situadas no contexto histórico-social da Era da Informação. Nele, as TIC são valorizadas como artefatos ou instrumentos nas tarefas diárias do docente dentro e fora da sala de aula. Em segundo lugar, observamos que os participantes propóem atividades em que os alunos precisariam lidar com os recursos computacionais no cotidiano do curso, dentro da sala de aula e / ou fora dele, exemplos que podem ser observados a seguir:

[...] nos cursos que ofereci a partir de 2004, fossem ou não sobre o uso da Internet, optei por não mais levar meus alunos para aulas no laboratório de Informática e, em seu lugar, solicitar que eles realizassem em casa quaisquer tarefas que exigissem o uso da Internet (Vivência Profissional de Karina, 2008).

No trecho mencionado, podemos verificar que os alunos também são postos como usuários das TIC, seja por atividades propostas em sala de aula, seja fora dela. Assim, para que os graduandos possam se cadastrar efetivamente nas listas ou grupos de discussão, Karina prescreve os procedimentos de uso de grupos online para seus alunos:

A atividade desenvolvida no laboratório visava ao cadastramento dos alunos no Yahoo Grupos para que tivessem acesso a todas as facilidades oferecidas pelo serviço, e não apenas recebessem por e-mail as mensagens distribuídas pela lista de discussão criada para a disciplina. $\mathrm{Na}$ aula no laboratório, os alunos receberam por escrito as instruçôes passo a passo para acessarem o Yahoo Grupos e se cadastrarem (Vivência de Karina, 2008).

Em terceiro lugar, outra característica do trabalho docente é o fato de ele ser pessoal, como caracteriza Machado (2009; 2010). Nos dados, podemos perceber que cada participante mostra usos distintos para as TIC. Samuel, por exemplo, diz fazer uso das TIC fora da sala de aula, via plataforma Moodle, 
em que pode armazenar dados diversos, agendar atividades com seus alunos e promover chats acadêmicos:

Em nossa universidade podemos dispor de uma plataforma Moodle em que montamos o curso, colocamos materiais e disponibilizamos tarefas com agendamento e textos digitalizados. (Vivência Profissional de Samuel, 2008).

Já Simone diz fazer outro uso das TIC: ela as utiliza na internet e em sites como youtube, para que os alunos busquem informações:

As aulas de inglês que dou ocorrem em ambientação presencial. Vou descrever uma unidade que elaborei - não uma aula específica - de um curso de inglês com foco nas habilidades de produção e compreensão oral. Nessa unidade, os alunos, divididos em grupos, têm que escolher um gênero, achar esse gênero (pra isso eles usam principalmente o youtube) e trazer esse material para a aula pra que todos assistam, discutam, etc. (Vivência Profissional de Simone, 2008).

Karina, por sua vez, além dos usos citados pelos outros participantes, utiliza as TIC para a preparação de suas aulas, pesquisa, em atividades presenciais com alunos e a distância:

Uso as TIC em minhas aulas na Faculdade de Letras da UFRJ de três formas: a) em sala de aula com os alunos (por exemplo, fomos para o lab ou usei uma apresentação com datashow); b) para preparar a aula (por exemplo, fiz buscas na Internet para encontrar textos relevantes); c) para complementar a distância uma aula presencial (por ex., continuamos discutindo via lista de discussão um tópico levantado em sala de aula presencial). (Vivência de Karina, 2008).

Retomando a questão da apropriação, observamos que a participante Karina é a que mais faz usos diferentes das ferramentas computacionais em seu trabalho docente, envolvendo desde a preparação até a própria aula, a saber:

- preparação de aulas da graduação e pós-graduação, por meio de pesquisas de material científico, na organização de slides e material para as aulas;

- no momento das aulas de graduação e pós-graduação, pelo uso de laboratórios computacionais ou notebook, com ou sem acesso à rede;

- na pesquisa, como integrante do Programa Interdisciplinar de LA, na orientação de estudos que focam o uso das TIC na educação. 
Diferentemente de Karina, Simone faz uso dos recursos computacionais para promover a prática das habilidades de leitura e conversação em sala de aula. Para ela, o trabalho docente é representado pela elaboração da aula, que tem suas atividades colocadas em prática pelos alunos. Simone é a participante que diz fazer uso de outras tecnologias além das TIC, como vídeo, em sala de aula. $\mathrm{O}$ uso das TIC para essa participante está relacionado às tarefas dos alunos de forma que:

- os alunos possam escolher um gênero usando a internet, especialmente o youtube; e

- as atividades apresentadas pelos alunos possam ser acessadas via $b l o g$.

Com base nos dados de Samuel, o participante utiliza, especificamente, computador, internet e a plataforma Moodle em seu trabalho fora de sala de aula presencial, e para as seguintes atividades:

- armazenagem de materiais diversos na plataforma Moodle;

- agendamento de tarefas com os alunos;

- promoção de discussões em chats sobre o conteúdo ou artigos fora do horário de sala de aula.

Assim, o trabalho com as TIC, embora seja prescrito de modo genuíno para todos, pelos órgãos governamentais, é efetivamente realizado de diferentes modos. Em suma, o que vemos nesses textos é que ocorrem representações diferentes para o uso das TIC. Cada um as emprega segundo seus conhecimentos e objetivos.

Em quarto lugar, o trabalho docente é também considerado como uma atividade instrumentada (MACHADO, 2009; 2010). Nos textos analisados, os computadores e seus periféricos, internet, sites diversos, como o youtube; blogs; datashow; programas de apresentação como PowerPoint; ambientes virtuais de aprendizagem como o Moodle, lista de discussão ou grupos como o yahoo groups; ferramentas de pesquisa e filmadoras aparecem como instrumentos privilegiados, como podemos ver nos trechos a seguir:

$\mathrm{Na}$ verdade, no caso destas disciplinas, não apenas a lista de discussão é usada, mas outros serviços oferecidos pelo Yahoo Grupos, como Arquivos, Agenda, Links, Banco de dados, Fotos, dependendo dos interesses e necessidades de cada turma. Na lista de discussão destas disciplinas, os alunos também interagem entre si e, portanto, a interação não fica limitada à interação comigo, a professora (Vivencia Profissional de Karina, 2008). 
Podemos observar também que além de mobilizar todo o seu ser psicológico, emocional e conhecimentos -, o professor ainda precisa de conhecimentos específicos na área da computação para fazer uso das TIC e também para letrar digitalmente alunos que não sabem lidar com as ferramentas computacionais, ou que não estão tão habituados a elas.

Em quinto lugar, o trabalho docente também é interpessoal. Nos textos, essa característica se mostra na relação entre professor e aluno ou professor e instituição. Por exemplo, para exercer a tarefa de levar os alunos ao laboratório, Karina precisa da autorização de outros - no caso, do diretor da faculdade, enquanto Samuel menciona a participação discente nas atividades realizadas na plataforma utilizada com os alunos:

Como o uso do laboratório de Informática para aulas é restrito (exige autorização por escrito da direção da faculdade para posterior agendamento no laboratório de acordo com a disponibilidade dos computadores, que, por vezes, não estão em pleno funcionamento). (Vivência de Karina, 2008).

A galera participa, se coloca, pergunta bastante, sentem-se mais a vontade para se posicionar e a atividade rende bastante. (Vivência Profissional de Samuel: 2008).

Em relação aos impedimentos encontrados para o uso das TIC, eles são representados nos textos de Karina e Samuel. Os dois enfrentam o problema da falta de laboratórios de informática para suas atividades; os alunos de Samuel têm dificuldade de acesso ao computador e à internet e, por isso, não participam dos chats acadêmicos; na instituição de Karina, há muita burocracia para a utilização dos laboratórios, que nem sempre funcionam plenamente, ou não suprem as necessidades da docente e seus alunos.

Diferentemente dos professores da instituição pública, que indicaram que utilizariam as TIC dentro e fora da sala de aula, nos textos dos professores pertencentes às universidades particulares, foram apontados usos das TIC de modo geral. Esses não especificaram claramente se o uso de tais recursos computacionais ocorria dentro ou fora da sala de aula. Assim, as representações sobre o uso das TIC são semelhantes às representações dos professores que trabalham em universidades públicas. A primeira característica semelhante está no fato de os alunos também serem considerados usuários das TIC: 
Além do uso desse tipo de material, os alunos aprenderam a melhor usar o Powerpoint uma vez que, nas suas apresentações no final do semestre, precisariam usar o recurso. Claro q levei o projetor multimídia e o notebook para q eles pudessem apresentar seu trabalho final (Vivência Profissional de Adriana, 2008).

Com base nos trechos anteriormente citados, vemos que além dos professores, os alunos deveriam ter conhecimentos na área da computação (básicos e avançados), para realizar algumas atividades, como a apresentação de slides. No caso de Adriana, os alunos também utilizam as TIC para apresentações orais.

A segunda característica semelhante é o trabalho, considerado pessoal. Nos textos são mencionados usos diferentes das ferramentas computacionais:

Em 2002, na UNINOVE, recebi a tarefa de montar uma disciplina onde $[s i c]$ os alunos do curso de tradução fossem apresentados às principais ferramentas computacionais (Vivência Profissional de Fernanda, 2008.).

Verificamos ainda que os recursos tecnológicos foram apropriados de formas distintas para realização de tarefas e atividades diferentes. Nos textos de Adriana, detectamos que as TIC são utilizadas ao longo dos anos em contextos diferentes, e que os usos representados são: aulas presenciais com uso de slides e vídeos baixados pela internet, aulas em cursos a distância e semipresenciais; inserção de disciplinas semipresenciais no curso de Letras; orientação de trabalhos de iniciação científica sobre TIC; e desenho de cursos semipresenciais.

Nos textos de Fernanda, as TIC são utilizadas para ministrar conteúdos relacionados às disciplinas que integram o curso de Letras / Tradução e de Computação, como processador de texto, glossário, listas de discussão, dicionários e redes sociais. Já nos textos de Flor, o uso das TIC é específico para a disciplina de Literatura Norte-Americana / Inglesa, e os recursos utilizados são a lista de discussão, e-mails, armazenamento de arquivos e uso de slides nas aulas. Em síntese, essas representaçôes nos mostram que as ferramentas computacionais são utilizadas de formas distintas e de acordo com os objetivos do professor.

Outra semelhança está no uso de instrumentos no trabalho docente, representados por computador, projetor, datashow, slides, sites diversos, programa de apresentação de slides, grupos de discussão, ambientes virtuais de aprendizagem. Percebemos que cada uma das professoras faz uso desses instrumentos, de acordo com seus objetivos e de maneira a facilitar o seu trabalho: 
O conteúdo programático contempla processadores de texto, pesquisa na internet tanto de terminologia quanto de conteúdo por meio de busca booleana, busca por glossários e dicionários online, redes de socialização (comunidades, listas e fóruns de discussão), tradutores automáticos (gratuitos e comerciais), memória de tradução (Trados e Wordfast) e critérios para análise das informaçôes vindas da web. (Vivência Profissional de Fernanda, 2008.).

A interpessoalidade é outra característica semelhante verificada nos textos, sendo representada pela presença da instituição e dos alunos:

Sendo assim, todos os slides das aulas e sites com assuntos sobre os autores e obras estudados são enviados para o grupo. Todos recebem as informaçōes e podem se preparar para a aula e ver os tópicos que serão estudados naquela aula. $\mathrm{Na}$ atual instituição onde leciono, o mesmo conteúdo programático é abordado dentro da disciplina "Versão da Língua Inglesa”, ministrado em laboratório de informática com carga horária anual de 72 h/a. (Vivência Profissional de Fernanda, 2008.).

Finalmente, no que tange a impedimentos, nos textos produzidos pelos docentes que trabalham em universidades particulares não há menção à falta de laboratórios, acesso a equipamentos para uso em sala de aula ou qualquer outro tipo de obstáculo à utilização das TIC.

\section{Considerações Finais}

Pelos textos analisados, verificamos que as representações sobre o uso que os docentes universitários de Língua Inglesa dizem fazer das TIC são semelhantes para os professores que trabalham nas universidades públicas e para os docentes que trabalham nas universidades particulares. Em ambos os casos, com base nas análises das produções textuais, foi verificado que as TIC são utilizadas em contextos distintos e de acordo com os objetivos dos professores. No entanto, para que isso ocorresse, foi necessário que os artefatos computador, internet e outros fossem transformados em instrumentos.

Observamos ainda que as representações construídas nos textos estão relacionadas às características sobre o trabalho docente levantadas por Machado (2009; 2010), e que dois agentes presentes neste trabalho são as instituições de ensino em que os professores trabalham e os alunos para os quais ministram suas aulas. Verificamos também que a dicotomia instituição pública e instituição particular fez diferença nos impedimentos do trabalho. Nos textos 
dos docentes que pertencem à primeira, foram mencionadas a falta de laboratório e a dificuldade de acesso às TIC na instituição em que esses docentes trabalham. Esse mesmo problema não foi identificado nos textos dos docentes que pertencem à universidade particular.

Os resultados indicaram que, pelas representações sobre o uso das ferramentas computacionais, esse uso pode ser mais adequado quando os participantes se apropriam dos recursos, ou seja, quando esses recursos deixam de ser artefatos e se tornam instrumentos, como indicam Verillon e Rabadel (1995) e Machado (2010).

Observamos ainda que, por meio da apropriação, cada docente traçaria seus próprios objetivos no uso das TIC e desenvolveria estilos diferentes ao usálas; exemplificando, enquanto Karina utiliza os recursos computacionais para ministrar suas aulas e realizar pesquisas, Adriana as usa para desenvolver e desenhar cursos semipresenciais. Cada participante desenvolveu seu próprio estilo ao fazer uso dessas tecnologias, de acordo com suas necessidades, objetivos, tarefas e impedimentos. Concluímos que, independentemente da instituição ser pública ou particular, as características do trabalho docente são semelhantes em ambos os tipos de instituição. Com a apropriação das TIC, os docentes podem fazer usos distintos desses instrumentos de acordo com os seus objetivos.

\section{Referências Bibliográficas}

ABREU-TARDELLI, L. O trabalho do professor em $\mathrm{EaD}$ na lente da legislação. In: MACHADO, A. R. O ensino como trabalho: uma abordagem discursiva. Londrina: Eduel, 2004, p. 169-197.

AMIGUES, René. Trabalho do professor e trabalho de ensino. In: MACHADO, A. R. O ensino como trabalho: uma abordagem discursiva. Londrina: Eduel, 2004. p. 35-53.

BRONCKART, J.-P. Atividade de linguagem, textos e discurso: por um interacionismo sociodiscursivo. 2. ed. Trad. Anna Rachel Machado; Péricles Cunha. São Paulo: Educ, 2007.

BRONCKART, J.-P. O agir nos discursos: das concepções teóricas às concepçôes dos trabalhadores. São Paulo: Mercado das Letras, 2008.

BRONCKART, J.-P. Posfácio. Ensinar: um métier que, enfim, sai da sombra. In: ABREU-TARDELLI, L. S.; CRISTOVÃO, V. L. L. O trabalho do professor em uma nova perspectiva. Campinas, Mercado de Letras, 2009, p.161-174. 
BRONCKART, J.-P. Por que e como analisar o trabalho do professor? In: MACHADO, A. R.; MATÊNCIO, M. L. M. Atividade de linguagem, discurso e desenvolvimento humano. Campinas: Mercado de Letras, 2006.

BRONCKART, J.-P.; MACHADO, A. R. Por uma concepção ampliada do trabalho do professor. In: GUIMARÃES, A. M. M, MACHADO, A. R.; COUTINHO, A. O interacionismo sociodiscursivo: questôes epistemológicas e metodológicas. Campinas: Mercado de Letras, 2007, p.77-100.

CARNEIRO, A. L. M. Teoria do currículo: contribuição para uma breve reflexão sobre o papel do professor universitário nos cursos de licenciatura. E-Curriculum, v. 1, n. 1, dez- jul. 2005-2006.

FERNANDES, C. M. B. Docência universitária e os desafios da formação pedagógica. Interface - Comunicação, Saúde, Educação. Botucatu, v. 5, n. 9, 2001. INSTITUTO NACIONAL DE ESTUDOS E PESQUISAS EDUCACIONAIS ANÍSIO TEIXEIRA. Censo da Educação Superior de 2007. Disponível em: $<$ http://portal.inep.gov.br/web/censo-da-educacao-superior/evolucao-1980-a2007>. Acesso em: 13 maio 2010.

INSTITUTO NACIONAL DE ESTUDOS E PESQUISAS EDUCACIONAIS ANÍSIO TEIXEIRA. Resumo Técnico do Censo de Educação Superior 2007. Disponível em: <http://portal.inep.gov.br/web/censo-da-educacao-superior/ resumos-tecnicos>. Acesso em: 14 maio 2010.

MACHADO, A. R.; BRONCKART, J.-P. (Re)configurações do trabalho do professor construídas nos e pelos textos: a perspectiva metodológica do Grupo ALTER-LAEL. In: ABREU-TARDELLI, L.S.; CRISTOVÃO, V. L. L. $O$ trabalho do professor em uma nova perspectiva. Campinas, Mercado de Letras, 2009. p. 31-77.

MACHADO, A. R. Trabalho prescrito, planificado e realizado na formação de professores: primeiro olhar. In: ABREU-TARDELLI, L. S.; CRISTOVÃO, V. L. L. O trabalho do professor em uma nova perspectiva. Campinas, Mercado de Letras, 2009. p.79-99.

MACHADO, A. R. Ensino de gêneros textuais para o desenvolvimento do professor e de seu trabalho. In: SERRANI, Silvana. (Org.). Letramento, discurso e trabalho docente: uma homenagem a Ângela Kleiman. Vinhedo: Horizonte, 2010. v. 1, p. 148-156.

MACHADO, A. R. Material Didático: Artefato ou Instrumento no Trabalho Docente? Disponível em: <http://www.youtube.com/watch?v=TADPyUTAok>. Acesso em: 20 jul. 2010. 
MAINGUENEAU, D. Análise de textos de comunicação. Trad. Cecília P. de Souza-e-Silva; Décio Rocha. 5. ed. São Paulo: Cortez, 2008.

MARTÍNEZ, J. H. G. Novas tecnologias e o desafio da educação. In: TEDESCO, J. C. (Org.). Educą̧ão e novas tecnologias: esperança ou incerteza? São Paulo: Cortez; Buenos Aires: Instituto Internacional de Planeamiento de la Educacion; Brasília: Unesco, 2004. p 95-108.

MINISTÉRIO DA EDUCAÇÃO. Parecer CNE/CES 492/2001. Disponível em: $<$ http://portal.mec.gov.br/cne/arquivos/pdf/CES0492.pdf>. Acesso em: 11 jan. 2010.

MOROSINI, M.C. Professor do Ensino Superior: identidade, docência e formação. Brasília: Instituto Nacional de Estudos e Pesquisas Educacionais, 2000.

PIMENTA, S.G.; ANASTASIOU, L. G. C. Docência no Ensino Superior. 3. ed. São Paulo: Cortez, 2008.

ROZENDO, C. A. et al. Uma análise das práticas docentes de professores universitários da área da saúde. Revista Latino Americana de Enfermagem. Ribeirão Preto, v. 7, n. 2, p.15-23, abr. 1999.

VERILLON P.; RABARDEL P. Cognition and artifacts: A contribution to the study of thought in relation to instrument activity. European Journal of Psychology in Education, v. 9, n. 3, p. 77-101, 1995.

VIDAL, D. E. Até que ponto o professor universitário está preparado para enfrentar o desafio do Século XXI? Tuiuti: Ciência e Cultura. Curitiba, n. 28, p.45-66, mar. 2002.

Recebido em 18/10/2011. Aprovado em 25/1/2012. 